\title{
Informed Strategies of Political Action in IP-Based Social Media
}

\author{
Andrea Knaut \\ Informatik in Bildung und Gesellschaft, Humboldt University, Berlin, Germany \\ knautainformatik.hu-berlin.de
}

\begin{abstract}
Political campaigning involves the intense usage of all possible media that the campaigners can afford to reach as many potential supporters as possible. Networked information technologies provide an endless source of applications and means of communication. When using computer technologies as a campaigning medium, it is essential to carefully assess the efforts concerning infrastructural and social requirements in consideration of the benefits gained. Therefore, the intertwined dimensions of political campaigning - content, infrastructure, community, protection of activists, planning, and archiving - are discussed as related to the involvement of IP-based media.
\end{abstract}

Keywords: computerized activism, electronic civil disobedience, political Internet campaign, participatory campaign, social movement, IP-based social media.

\section{Introduction}

In the late 1990s, Stefan Wray, member of The Electronic Disturbance Theater, divided Internet usage by extra-parliamentary grassroots social movements into five categories of "direct action Net politics": Computerized Activism, Grassroots Infowar, Electronic Civil Disobedience (ECD), Politicized Hacking (Hacktivism) and Resistance to Future War [1]. Networking technologies prior to the Internet Protocol, for example the Unix-to-Unix Copy Protocol (UUCP) or various bulletin-board systems, were already being used for political campaigns in the 1980s, yet it was the Internet Protocol (IP) that inspired the name Internet and which is now known for providing solutions to almost any problem. For example, concerning its capacities to be used as a political activist's medium, the "Internet allows for the convergence of meetings, debates, and research in one convenient and fast medium that greatly enhances not only activists' organizational capabilities but also the ability of activists to react to a constantly changing world in a timely manner" as the author metac0m states in the text 'What is Hacktivism? 2.0' [2].

In this article I will take a closer look at the basic structural requirements for integrating IP-based social media or the Internet into political campaigns.

Speaking of IP-based social media instead of the Internet in the title of this text is an attempt to explicitly connect media and social to Internet while still relating the 
technology and its history: Internet represents - as a historical name - the central idea of the implementation of an open architecture, all of which could globally network any computers regardless of their being parts of different networks. It was meant as an "Internetworking Architecture" [3]. Technically, IP is only one possible implementation of a certain part of this idea, which breaks down into several subconcepts such as the layer model of data transmission, packet switching, or end-toend principle. The IP is herein the technical realization of packet switching, and has established itself as the World Wide Web's underlying technology along with the Transport Control Protocol (TCP). IP-based social media are an implementationindependent computer network which underlies the constantly expanding plethora of media applications that allow for social interactions. Considering this, one could briefly pause to reflect on the triple tautology of IP-based social media and afterwards continue using the synonyms Internet, Net, Web.

The concept of political campaigning is understood according to Ulrike Röttger's definition: "Campaigns are dramaturgically constructed, thematically limited, terminable communication strategies to generate public attention using a set of different communicative tools and techniques [...]. Targets of campaigns are: raising awareness, building confidence in their own credibility and generating support for their own intentions and/or subsequent action" (my translation, [4]). Based on the idea of grassroots campaigning, according to Lohmeier, the actors of a campaign are to be included in the term: "A political campaign can be described as participatory if it can be influenced by everybody who should and wants to participate in it [...]" (my translation, [5]).

The structural problem areas of Internet-based participatory campaign politics, described below, are exemplified in the campaigns 'Initiative in Memory of Oury Jalloh' and 'Deportation.Class'. These are/were mainly German based extraparliamentary initiatives in the field of human rights policy that gained a lot of attention. Both involved the Web "in a timely manner," but quite differently. These grassroots movements are described briefly as follows.

\section{1 'Initiative in Memory of Oury Jalloh'}

"Break the Silence" is the motto of the 'Initiative in Memory of Oury Jalloh' [6]. It was founded as a consequence of asylum seeker Oury Jalloh being burnt to death on January 7, 2005 while in Dessau police custody. Oury Jalloh's parents joined the prosecution in a lawsuit against two police officers for grievous bodily harm with fatal consequences and involuntary manslaughter. An entry on the website of the organization 'Caravan for the Rights of Refugees and Migrants' keeps a reader available on the Net, explaining to "all clubs, organizations, groups and individuals [how] to commit [...] publicly to the demands of the "Initiative in Memory of Oury Jalloh' and to actively support it [...]". They propose, amongst other things, "making the demands of the initiative publicly known in your community (e.g., Internet, newspapers, magazines, mailing lists, etc.) [... and] sending your own experiences with police brutality and judicial arbitrariness to our contact address. We want to 
collect and document the cases to show that the case of Oury Jalloh is not an isolated one and that structural racism and police brutality exist" (my translation, [7]).

Accordingly, activists of different groups and individuals persistently arranged memorial rallies, demonstrations and an intensive monitoring of the judicial proceeding [8]. The case has received quite a lot of attention in the conventional mass media: there are numerous film, radio and press contributions. ${ }^{1}$

The initiative's website is hosted by the blog-publishing service Wordpress.com and there are relatively well maintained records of Oury Jalloh in the German [10] and English Wikipedia [11].

\section{2 'Deportation. Class Campaign'}

Since 2000 the Deportation.Class Campaign [12] has been supported by a broad antiracist, decentralized Europe-wide alliance "against the deportation business" [13]. It aimed at making it widely known that airlines earn money with forced deportations. The violent death of refugee Aamir Ageeb during deportation was the campaign's motive [14]. A spectacular online protest explicitly based on the concept of Electronic Civil Disobedience was part of the campaign. On June 20, 2001 thousands of people paralyzed Lufthansa's servers for almost two hours with a distributed denial of service (DDoS) attack [15]. Their calculation of attracting a lot of public attention eventually reached the mass media. ${ }^{2}$

The campaign never ended officially but its online content is archived on [12] and has not been extended since 2003. The goal of stopping the deportation business was only partially achieved. I will return to both campaigns again in the following text which analyzes the cornerstones of an Internet-based campaign, the most important element of which concerns:

\section{Content First}

A problem and political demands connected to it need to be written out in full on many levels. It is necessary to address people with similar problems, to win supporters, to persuade others and to lead discussions with reproducible, solid arguments. These are usually published in brochures, leaflets, posters, press releases, and other publications with differing complexities of textual content. Additionally, there could be movies, sound files, perhaps even tactile elements, whole performances, in short: a campaign usually talks to all the human senses, its activists are looking for a broad multimedia implementation.

Initiators and supporters, however, should be encouraged to discuss principal aims, underpinning them with arguments. The reasons for participation and support - the analysis, interpretation and implementation of ideas - ideally constitute a truly

\footnotetext{
${ }^{1}$ The outstanding include the ARD documentary "Tod in der Zelle - Warum starb Oury Jalloh?", the Human Rights Film Award-winning movie "Oury Jalloh" [9] and many press reports, partly documented in [8] and [9].

${ }^{2}$ Some reactions of the press have been documented at [16].
} 
participatory campaign. "In the ideal case, the difference between the initiators of a campaign and dialogue groups dissolves in a process of mutual influence and involvement; the objects of a campaign become themselves the subject of the campaign and thus experience themselves as politically decisive persons" (my translation, [5]). In conventional models of political interaction - without the Internet - this is achieved through workshops or alliance meetings.

The Internet can now broaden this discussion and strongly modify spatial and temporal constraints. In part, this initially can be done as unidirectional content provision using communication channels such as blog entries, postings on mailing lists, forums, in social networks, newsletters, film or image hosting, or by creating one's own campaign website. Furthermore, research opportunities are linked to for background information. Most of the chosen content provided on the Net can easily become bidirectional if people use the functions to comment and reply. ${ }^{3}$ The range of ways to present and discuss content on the Net is versatile, as still newer tools evolve and commercial content providers change. It needs to be structured beyond specific software labels, structured according to the degree of content processing on the Net; to the number of presentation channels being used, to the degree of the campaigner's creation of their own design; according to the accessibility by potential recipients including, of course, barriers of language, writing, reading, and physical access (see also the following section on 'infrastructure'); according to respectability of the resource being used; and according to the echo in those media not controlled by the campaigners. This echo might be influenced in an advantageous way, but to some extent negative dynamics may also develop because a campaign is always a part of a complex discourse. ${ }^{4}$ The degree of influence on the shape and durability of Internetsupplied content is strongly linked to the infrastructure requirements described later. Smaller initiatives often rely on the many existing commercial and semi-commercial specific application providers, where content can be freely designed only in moderation, yet in most cases relatively intuitively. Especially popular are blog and wiki hosts, video and photo portals, social networks, and online petitions. The administrative structures of these providers are often opaque and impersonal. So too is the administration of the content, the servers, databases, and backups used. Usually one is required to register before being able to communicate and/or provide content. Preferably very creative information should be used as personal data to this end (see section 'protection of individual activists'). Moreover no one is liable for the great risk of sudden data loss or spying on surfers' behavior via cookies or static IP addresses. Posting and retrieval of content such as streaming media or images almost always requires modern browsers and either large bandwidth or a lot of patience and

\footnotetext{
${ }^{3}$ There is also software like LiquidFeedback or Adhocracy that enhances political discussions by computer-based consultation and intervention processes. There is petition, bookmarking, calendar software and so forth.

${ }^{4}$ Discourses are interpreted here in the Foucauldian sense as "systems of knowledge formation, that control the conditions for exclusion and production of statements. They manifest as ensembles of statements, in which a subject is negotiated on a societal level." They always "depend [...] on platforms of social exchange, i.e. media" (my translation, [17]).
} 
the graphical complexity or inefficient programming of hosting systems can also lead to too much traffic.

If I consider the two example campaigns given above: there has been a huge dynamic in the content production accompanying the Oury Jalloh campaign. The 'Initiative in Memory of Oury Jalloh' provides its press releases and reports in an online blog. The movies, radio broadcasts, and the many press reports are an echo of good public relations through a diverse and widely-dispersed community. The actual website is kept minimal, probably maintained by very few people. The contents are easily accessible for everyone with Internet access. There are some multilingual presentations and moderated comments.

Ultimately, the campaign depends mainly on the on-site presence in real life, the commemoration marches, and the anti-racist lobbying. The blog entries are used by activists especially for getting information about where and when the next direct onsite actions will occur, besides the painstaking trial reports and the links to other reports.

The web content of the Deportation.Class campaign distinguished itself by the fact that the campaigners created a very professional specifically elaborate design and launched it on a domain labeled with the campaign's name. In keeping with the guerilla communication-like character of the campaign [18], the design of the website and any printed materials strongly echoed the former Corporate Design of Lufthansa's advertising materials. One could order the printed materials through the online shop. Partial successes, reporting and links to reports have been documented in the campaign's log. The broad, pan-European network and the many decentralized activities of the alliance have been documented on the multilingual site http://www.deportation-alliance.com. Altogether the campaign thrived on the enormous ingenuity of the activists in how to circulate the central objectives. This included the purchase of Lufthansa' shares to facilitate protests at shareholder meetings against forced deportations tolerated by Lufthansa. Other activists regularly dressed in flight attendants' uniforms and distributed campaign materials at airports or tourism fairs. The online demonstration in the form of a DDoS attack against the Lufthansa website on June 20, 2001 was another central form of action. According to the district court of Cologne, the protest software was launched from 13,614 different IP addresses. Lastly, Lufthansa filed a complaint claiming to have suffered economic damage from the attacks [19]. The actual prior mobilization for the online demonstration had mainly been run off-line. The campaign Deportation.Class and its well-designed paper materials were extremely professional considering that it was a matter of autonomous extra-parliamentary activism.

\section{Infrastructure}

Both the creators of campaign content and the potential recipients most notably need access to a sufficiently modern computer with sufficiently fast network access and enough time online. If any of these core infrastructural components are not available for the initiators or the central target group, the use of the Internet medium is not a priority to take into consideration. Furthermore at this point, the accessibility of a 
website in terms of poor environmental conditions, including non-existent computer and/or network access or extremely outdated, slow, or unaffordable technology, rank among the main structural marginal conditions as well. Finally, the accessibility in accordance with the "Web Content Accessibility Guidelines 2.0" is also concerned. "Following these guidelines will make content accessible to a wider range of people with disabilities, including blindness and low vision, deafness and hearing loss, learning disabilities, cognitive limitations, limited movement, speech disabilities, photosensitivity and combinations of these. Following these guidelines will also often make your Web content more usable to users in general" [20].

The core infrastructure components of computerized activism thus correspond with the problem of the so-called digital divide, that spells out the Net's accessibility as a social privilege. Relating to above mentioned criteria Kling's two-level-model of the digital divide fits best: a computerized political campaign needs technological access: "the physical ability of suitable equipment, including computers that are of adequate speed and equipped with appropriate software for a given activity" as well as social access: "know-how - a mix of professional knowledge, economic resources, and technical skills - for using technologies in ways that enhance professional practices and social life" (as cited in [21, p. 96]). This view is appropriate here, though the term digital inequality is preferred and Zillien developed a more differentiated definition that resolves the inherent dichotomy of digital divide [p. 93]. Digital inequality includes the "technological, socio-economic and political realities of Internet use" (my translation, [21, p. 90]).

With regard to technological access, in the worst case there is neither a computer nor access to a network with high bandwidth availability. Confronted with that situation an activist can still use - if available - public institutions, call shops, and asynchronous communication such as mail. On the basis of the given financially affordable and professionally usable time, time-consuming items in highly interactive, real time applications are rather discarded. Ultimately, even small, seemingly static and unidirectional communication draws further reactions: These may be requests for interviews, comments in forums, emails or calls. Some of it might already be anticipated in advance (e.g., text blocks or fact sheets could be prepared). Any communication tasks on the campaign should be delegated to as many supporters as possible. Everyone is also encouraged to take over responsibility in designing the campaign in regard to the participatory factor.

At best, it is possible to fall back on a volunteer provider with dedicated servers in a trusted environment connected to broadband access. The campaigners acquire their own domain names and possess full right of access to the web servers. This would allow for a lot of room to maneuver, but can cause delays with unnecessary tasks as well.

The aforementioned campaigning examples already necessitated various degrees of technical and social conditions on both the initiating side and the side addressed by activists. In particular, the Deportation.Class campaign required people with expertise in professional web design, programming the online-demonstration software, and in hosting everything. Especially for such a campaign, the use of a "friendly" host is recommended. A host like that offers reasonably protected areas if it comes to the 
interests of powerful institutions. Providing alternative medial infrastructure for noncommercial, self-organized extra-parliamentary grassroots movements is an old strategy comparable to the creation of free radios, small nonprofit printing shops and the like. This could be seen as politically conscious technological access provision. Examples in Germany are antira.info [22] and so36.net [23] that offer Internet services such as mailing lists, email, web space, online project management software for developers, or chat clients. Sometimes small companies also support such initiatives - for example, the Chaos Computer Club seeing themselves as "Europe's largest hacker association and for over 25 years mediators in the stress field of technical and social developments" (my translation, [24]) lists sponsorship by medium-sized ISPs like HostEurope GmbH, Speedbone, Nessus GmbH, Inter.net Germany GmbH, and nonprofit associations like Individual Network Berlin e.V. [25]. The voluntary association Individual Network Berlin e.V. offers modem or ISDN dial-up, leased lines, DSL connections, and Internet services [26].

\section{Community}

A supportive community is part of the social infrastructure. In the development of a community, perhaps even with organized allies, it is essential to the scope of a campaign to have people who support and disseminate information about the cause, who solve many of the issues mentioned above concerning physical infrastructure, and who discuss the topics and campaigning strategies. The community is made up of activists who join the activities, who raise money, who allocate offices, and who act protectively in cases of repression. They also use their online time to pass the concern to others. Word of mouth is very important whether online or offline. Talking about the campaign, linking it on and to the right spots is essential. In a truly participatory campaign, every contributor acts in an emancipated manner and the initiators of a campaign merge into the community.

\section{$5 \quad$ Protection of Individual Activists}

The Deportation.Class shows quite clearly the boundary between Computerized Activism and Electronic Civil Disobedience. As in the offline world, both of which can already have threatening consequences for the protesters. ECD is more likely to end up in small complaints - depending on the legal status of a person or of the country even in big complaints, imprisonment, or deportation. As a consequence of the Deportation.Class online demonstration, for example, the offices of the organizing group Libertad! have been searched, and computers and volumes were seized. The domain holder of www.libertad.de was accused in a lawsuit [19]. The Federal Crime Police Office tried to pursue all IP addresses back to their users as part of their investigations. The programmers of the protest software were not implementing proxy usage by intention to underscore the legality of the venture. In addition, plans to conduct the online demonstration were announced to the regulatory authority in 
Cologne [27]. Fortunately, the publication of the personal data behind the IP addresses failed at the time due to the refusal of the Internet service providers (ISP) [18]. Attempts by the authorities to acquire such IP addresses are less likely to fail now given the new telecommunications monitoring and surveillance regulation of 2002 in Germany and the consequent provision of the necessary interfaces to law enforcement authorities. However, the Federal Crime Police Office even then visited several institutions from which attacks were launched to try to get information about the users.

Anonymity as a means of protecting protesters is almost impossible to fully realize in the Net, especially if Internet services require mandatory registration and lots of social linking. A high degree of invisibility on the Net requires media literacy to ensure proper private browsing settings, usage of anonymizing services, and dataeconomical surfing. In addition, parts of the infrastructure would have to be housed by trusted providers who cannot be directly associated with initiators of ECD actions. Anonymous political action should be seen as impossible within the scope of the Internet. The protection provided for activists tends to come from the community acting in solidarity with activists facing repression. In every campaign, a real existing trust structure is essential for effective protection of endangered persons, and can probably not be fully built online.

Certainly, there may be a central disputable question, to what extent should communities account for political attitudes. Courageous people have to represent themselves as individuals, so that they display a level of persuasiveness. But ideas of justice, equality, or freedom from domination are universal and not tied to individuals. However, leaders, protagonists, or authors of important texts of a movement always play a key role. From religion to political ideologies to mass media discourses, both the author and the fictitious protagonist are important for the protest narratives. Thus, actors are formed with whom protesters would identify. An anarchistic approach to solving this problem results in the use of collective pseudonyms as Luther Blisset ${ }^{5}$ or Guy Fawkes ${ }^{6}$.

Overall, the role in which individuals perform should always be balanced based on political goals and the circumstances. There are also intermediate solutions. Responsible persons and participants of an activity do not always need to stand behind it with their name. At certain levels, pseudonyms, fictitious personal data can be useful; however, when it comes to the personal involvement of individuals, for

5 “'Luther Blissett' is a multi-use name, an 'open reputation' informally adopted and shared by hundreds of artists and social activists all over Europe since Summer 1994. For reasons that remain unknown, the name was borrowed from a 1980's British soccer player of AfroCaribbean origins" [28].

6 In 2008, 7,000 people protested against Scientology worldwide synchronously forming a "global protest movement known as Project Chanology, a concept devised by a leaderless, decentralised group calling itself Anonymous" [p. 96]. They wore masks - "Mirroring V For Vendetta, the Guy Fawkes masks are provided to the public by rebels in a dystopian fascist state, in order to enable the public to organise mass protests" [29, p. 102]. The Anonymous movement itself is, by the way, a very interesting object of study of current hacktivism or ECD. 
example, who bring charges of injustice against someone who is representative of many other persons concerned, an individualized trial can encourage a huge amount of solidarity for protestors, which is possibly an effective form of protection for them.

\section{$6 \quad$ Planning}

Right from the start, it should be clear how long a political campaign should last and what its different milestones will be. Of course, this can be changed later on, but a timeline helps in assessing the effort that can and should be spent on online communication. The capacities of an alliance cannot be bound for many years to one special topic. The Deportation.Class campaign gives a good example on this - it clearly focused on core events such as the shareholders' general meeting in 2001. The memorial movement for the death of Oury Jalloh is strongly oriented to the course of the lawsuit as well as to the continuous goal of keeping awake the memory of this peak of racist violence by state organs. But the character of a commemoration is not the same as a campaign's. Campaigning is not thought to be that open-ended.

\section{$7 \quad$ Archiving}

Documenting the history of a campaign is, therefore, implicitly or explicitly part of the same. Daily newspaper articles; radio and television broadcasts; and a campaign's own text documents such as reports and logs, photos, interviews, books, and all of its virtual and material scraps have to be collected and structured. That makes a lot of work and the new media makes the matter a little more confusing. Once the campaign has stopped, the feeds, tweets, and comments, briefly, the whole attention subsides and many sites become orphaned.

The problem of the transience of Web content is on the one hand a major challenge for libraries [30]. But, on the other hand, the uncontrollability of what remains and what disappears and of how non-vanishing is related to other data are precisely the challenges for new media in relation to privacy [31].

The non-profit organization Internet Archive, for example, crawls the web regularly automatically like a search engine for archiving purposes. The reliability of such services for documenting a campaign is questionable [30]. The collection and archiving of remotely scattered reactions, and the various copies and comments in different contexts can only be partially automated. One who wants to be the historian of her campaign and the reactions to it, has to write her own story. The 'Initiative in Memory of Oury Jalloh' is an example of this; it is to some extent a documentation campaign, whose own changes would in turn only be documented by Internet Archive with a few snapshots. The Deportation. Class campaign, however, has been partly swallowed as a primary source already as the domain was put out of use. Instead, the 'No Border network' has archived the websites of the deportation-class domain.

To this meta-level archiving many archaeological problems are connected (e.g., the illegibility of website artifacts if the formats on the Web are changing). 


\section{Conclusion}

A network-based, participatory campaign presupposes a freely usable Internet. So will the hacktivists be able to keep their self-set role as guards of a free network world?

"Hacktivism is a form of electronic direct action in which creative and critical thinking is fused with programming skill and code creating a new mechanism to achieve social and political change. Hacktivists are committed to securing the Internet as a platform for free speech and expression. This ensures that the Internet remains a medium for activism and an environment that facilitates the free flow of information" [2].

The Internet is seen as an open space permanently threatened and monitored. A high level of expertise, such as programming skills, is needed for its preservation. The use of the Internet is to that effect and concerning the discussed infrastructural provisions a social privilege. In the quote above, creative and critical thinking was not forgotten - for all the knowledge of the technology may not help anyone if the Internet is not understood as social and as medium. IP is, as said before, a basically interchangeable technology and does not make THE mythical difference, as the title suggests, for the offline world [32]. The Internet is, on the contrary, in many respects similar to the offline world in its social complexity, regardless of the technology: "The forms of control the Internet enables are not complete, and the freedom we experience stems from these controls; the forms of freedom the Internet enables stem from our vulnerabilities, from the fact that we do not entirely control our own actions" [33, p. 3].

\section{References}

1. Wray, S.: Electronic Civil Disobedience and the World Wide Web of Hacktivism. SWITCH New Media Journal 9 (1998),

http://switch.sjsu.edu/web/v4n2/stefan/index.html

2. metac0m: What is Hacktivism? 2.0 (2003),

http: / /www. thehacktivist.com/whatishacktivism.pdf

3. Leiner, B.M., Cerf, V.G., Clark, D.D., Kahn, R.E., Kleinrock, L., Lynch, D.C., Postel, J., Roberst, L.G., Wolff, S.: Brief History of the Internet,

http: / / www. internetsociety.org/internet/internet-51/

history-internet/brief-history-internet

4. Röttger, U.: Kampagnen. In: Jaren, O., Sarcinelli, U., Saxer, U. (Hg.) Politische Kommunikation in der demokratischen Gesellschaft. Ein Handbuch mit Lexikonteil, S. 667. Opladen, Wiesbaden (1998)

5. Lohmeier, T.: Inhalt braucht Form. Partizipatorische Kampagnenführung für eine emanzipatorische Linke - eine Einführung. rls standpunkte 1 (2009)

6. Break the Silence, Initiative in Gedenken an Oury Jalloh e. V., http: / / initiativeouryjalloh.wordpress.com/

7. Break The Silence, Inforeader Initiative in Gedenken an Oury Jalloh, http: / / thecaravan.org/node/702

8. Warum starb Oury Jalloh? Der Prozess, http://www . prozessouryjalloh. de/

9. Oury Jalloh, http://www. ouryjalloh-derfilm.de

10. Oury Jalloh,

http://de.wikipedia.org/w/index.php?title=

Oury_Jalloh\&oldid=100873633\#Einzelnachweise 
11. Oury Jalloh, http://en.wikipedia.org/w/index.php?title= Death_of_Oury_Jalloh\&oldid=471656087

12. deportation-class.com, http: / / www . noborder. org/archive/www. deportation-class.com/

13. deportation-class.com I campaign $\log$, http: / /www . noborder. org/archive/www. deportationclass.com/log/index.html

14. Dokumentationsseite Aamir Ageeb, http://www. aamirageeb. de

15. Kampagne Libertad! - Projekte: Online-Demo gegen Lufthansa (2001), http://www.libertad.de/inhalt/projekte/ depclass/onlinedemo/index.shtml

16. Index of archive, http://www. deportation-class.com/1h/presse http: //www. noborder. org/archive/www. deportationclass.com/lh/presse/

17. Fraas, C., Klemm, M.: Diskurse - Medien - Mediendiskurse. Begriffsklärungen und Ausgangsfragen. In: Dies (Hg.): Mediendiskurse. Bestandsaufnahme und Perspektiven, S. 1-8. Lang, Frankfurt am Main u.a (2005)

18. autonome a.f.r.i.k.a. Gruppe, Luther Blissett, Sonja Brünzels: Handbuch der Kommunikationsguerilla. Assoziation A, Berlin (2001)

19. Infomappe zum Prozess Online-Demo 2001, gegen Lufthansa (2001), http: / /www.scribd.com/doc/45267095/2001-OnlineDemonstration-gegen-Deportation-Asylsuchender

20. Web Content Accessibility Guidelines (WCAG) 2.0, http: / / www.w3 . org/TR/WCAG/

21. Zillien, N.: Digitale Ungleichheit. Neue Technologien und alte Ungleichheiten in der Informations- und Wissensgesellschaft. VS Verlag für Sozialwissenschaften, Wiesbaden (2009)

22. about antira.info, http://antira.info/about-antira-info/

23. so36.net e. V, http: //so36.net/

24. CCC, http://www. cCC.de/

25. CCC I Sponsoren, http://www. CCC.de/de/sponsors

26. IN-Berlin im Web: Darstellung IN-Berlin, http: //www. in-berlin.de/about/darstellung.html

27. Libertad!: Online-Demo vor Gericht. Ziviler elektronischer Widerstand oder Computersabotage? ak - analyse \& kritik - zeitung für linke Debatte und Praxis 492 (2005), http: / /www.akweb.de/ak_s/ak492/19.htm

28. Luther Blisset, http: / / www . lutherblissett . net/

29. Elliot, D.C.: Anonymous Rising. LINQ 36, 96-111 (2009)

30. Rauber, A., Kaiser, M.: Web Archivierung und Web Archive Mining: Notwendigkeit, Probleme und Lösungsansätze. HMD - Praxis der Wirtschaftsinformatik 268, S.35-S.43 (2009)

31. Schaar, P.: Der digitale Radiergummi und das Recht, vergessen zu werden (2010), https: / / www.bfdi.bund. de/bfdi_forum/showthread.php?1697-Derdigitale-Radiergummi-und-das-Recht-vergessen-zu-werden

32. Cannon, R.: Will the Real Internet Please Stand Up: An Attorney's Quest to Define the Internet. In: Telecommunications Policy Research Conference 2002. Social Science Research Network (2004)

33. Chun, W.H.K.: Control and Freedom. Power and Paranoia in the Age of Fiber Optics. MIT Press, Cambridge u.a. (2006) 